\title{
Prostaglandin-Mediated Effects on Growth and Markers of Biochemical Development in the Rat
}

\author{
J. NEU, ${ }^{(20)}$ R. G. HOFFMANN, AND W. N. CRIM \\ Department of Pediatrics and Biostatistics, The Medical College of Wisconsin and Milwaukee Children's Hospital, \\ Milwaukee, Wisconsin, USA
}

\begin{abstract}
Summary
Several markers of growth and biochemical development in the rat were studied after administration of prostacyclin $\left(\mathbf{P G I}_{2}\right)$ and 16, 16-dimethyl prostaglandin $E_{2}\left(16,16 D M P G E_{2}\right)$. Intermittent administration of $\mathrm{PGI}_{2}$ for 3 days to 10 - and 19-day-old animals, with subsequent sacrifice at 14 and 23 days, resulted in significant dose related decreases in growth at 23 days. Total sucrase and maltase (glucoamylase) activities were elevated compared to controls at 14 days. Total activities of these enzymes were decreased in postweaned 23-day-old animals, but specific activities per $\mathrm{mg}$ intestinal protein were not significantly different. 16, 16DM PGE administered continuously between day 10-16 of life caused alterations in growth as well as increases in sucrase and maltase (glucoamylase) activities. Exogenously administered prostaglandins, therefore, are associated with altered growth and markers of biochemical development in the rat.
\end{abstract}

\section{Abbreviations}

16, 16DM $\mathrm{PGE}_{2}, 16$, 16-dimethyl prostaglandin $\mathrm{E}_{2}$ GI, gastrointestinal

NEC, necrotizing enterocolitis

$\mathrm{PGI}_{2}$, prostacyclin

A paucity of data exists concerning the physiologic role of prostaglandins in the gastrointestinal tract of the developing fetus and neonate. Although these compounds elicit potent pharmacologic responses and are ubiquitous in the body, their therapeutic use causes some concern.

In adult animals prostaglandins may influence many aspects of gastrointestinal function including motility, secretion, mucosal blood flow, mucous production, and ulcer formation (1). Both PGE and lesser amounts of PGF are present in the organs of the GI tract $(2,13)$. PGI $I_{2}$ is also found in the rat stomach (12). It has gastric antisecretory and cytoprotective properties similar to those of $\mathrm{PGE}_{2}$ (14).

There is speculation that prostaglandins may protect the small intestinal mucosa from luminal insults by regulating mucous secretion. Robert (15) has shown that prostaglandins may have a "cytoprotective" effect on the GI tract. Gastric and small intestinal ulcers can be prevented, in a dose-dependent fashion, by oral and subcutaneous prostaglandin administration.

If the prostaglandins play an important role in vascular homeostasis, then alterations in their synthesis or pool sizes might produce aberrations in blood flow and pathologic consequences. Indomethacin decreases the rate of formation and changes the composition of gastric mucus in the dog, making it more susceptible to damage by acid and peptic digestion (10). It is known that synthesis of the mesenteric vasodilators $\mathrm{PGE}_{2}$ and $\mathrm{PGI}_{2}$ are blocked by indomethacin (3). It is, therefore, of concern that the use of prostaglandin inhibitors such as indomethacin might lead to an increase in the incidence of NEC by compromising mesenteric blood flow.
The use of prostaglandins in pharmacologic doses to maintain ductal patency in neonates with cyanotic congenital heart disease has been associated with side effects. Among these side effects are pyrexia, apnea, cutaneous flushing, hypotension, and long bone periosteal proliferation. The long term effects of exogenous administration of the prostaglandins on the development of the rapidly growing mammal is poorly understood.

The purpose of this investigation was to: (l) use an animal model to study the effects of certain prostaglandins on growth and (2) to investigate the alterations caused by prostaglandins in small intestinal disaccharidase content.

The data suggest alterations in somatic growth and intestinal biochemical development brought about by exogenously administered prostaglandins.

\section{MATERIALS AND METHODS}

Prostaglandins. Representatives from two classes of prostaglandins used in this study were $\mathrm{PGI}_{2}$ and $16,16 \mathrm{DM} \mathrm{PGE}_{2}$, generously made available by Dr. Mary Ruwart from Upjohn, Kalamazoo, Michigan. The methyl analogue of PGE was chosen for this study because it can be mixed with triacetin and infused continuously using osmotic minipumps.

Preliminary studies (16) have demonstated the stability of 16 , $16 \mathrm{DM} \mathrm{PGE}_{2}$ in triacetin. Less than $10 \%$ degradation of the 16 , $16 \mathrm{DM} \mathrm{PGE}_{2}$ triacetin solution in minipumps is seen over a 2-wk period. Both $\mathrm{PGI}_{2}$ and $16,16 \mathrm{DM} \mathrm{PGE}_{2}$ were chosen because of their previously described effects on the intestine $(14,15)$. Doses of the exogenously administered prostaglandins were chosen such that they would be in the range of the dose of $\mathrm{PGE}_{1}$ administered to the human neonate for maintenance of ductal patency.

Morphologic parameters investigated were total body, liver, kidney, gut, and lung weights after intermittent $P G \mathrm{I}_{2}$ and continuous $16,16 \mathrm{DM} \mathrm{PGE}_{2}$ administration to rat pups. Markers of biochemical intestinal development consisted of total small intestine protein, disaccharidase activities and aboral gradients of disaccharidase activity.

Experimental design. Prostacyclin was dissolved in a $0.2 \%$ glycine, $1.5 \% \mathrm{NaCl}, 2.5 \%$ mannitol buffer $(\mathrm{pH} \mathrm{10.5)}$ and injected subcutaneously three times a day with 0.2 cc doses of $0.1,0.2$, or $0.3 \mathrm{mg} / \mathrm{kg}$ to groups of five experimental animals. Littermate control pups were injected with $0.2 \mathrm{ml}$ of buffer alone. Experimental and control animals were sacrificed at 14 and 23 days of age after four days of treatment.

$16,16 \mathrm{DM} \mathrm{PGE}_{2}$ was administered in triacetin as a vehicle using Alzet osmotic minipumps (Palo Alto, California) with a $200 \mu$ liter reservoir, model 2002. Minipumps were inserted subcutaneously (at 10 days of age) in the abdominal area as recommended by the manufacturer under Fluothane anesthesia after a 3-h fast. Experimental (10-day-old) animals were continuously infused with 16 , 16DM PGE 2 at a rate of $0.3 \mu \cdot \mathrm{kg}^{-1} \cdot \mathrm{min}^{-1}$, based upon the weight of the animal at 10 days. Control animals were similarly infused with triacetin alone using the osmotic minipumps. The experimental and control animals were sacrificed at 16 days of age. 
Aboral gradients of small intestinal disaccharidase activity were examined in animals, which were administered $\mathrm{PGI}_{2}$ for 4 days and $16,16 \mathrm{DM} \mathrm{PGE}$ for 6 days. All animals were sacrificed at similar times of day.

Analyses. Gross morphologic measurements included total body, total small intestine, liver, lung, kidney, and brain weights. Gut lengths were measured from pylorus to the ileocecal junction. Entire small intestines were gently flushed with cold saline and homogenized 1:5 (small intestinal weight:volume of buffer) in 10 $\mathrm{mM}$ sodium phosphate buffer, $\mathrm{pH} 6.0,0.002 \%$ Triton $\mathrm{X}-100$ for biochemical analyses. The aboral gradient analyses were performed on nine equally sized segments of intestine from pylorus to the ileocecal junction after flush with cold saline and homogenization. Units of enzyme and protein mass were added together from the segments for determination of the entire small intestinal units of enzyme activity and specific activities. Fresh homogenate was precipitated in $0.4 \mathrm{~N}$ perchloric acid (1:3) for protein assay.

Disaccharidase activities were assayed at $37^{\circ} \mathrm{C}$ and $250 \mu$ liter reaction volume in $50 \mathrm{mM}$ sodium phosphate buffer, $\mathrm{pH} 6.0$, using $0.04 \mathrm{M}$ sucrose (for sucrase activity), $0.0156 \mathrm{M}$ maltose (glucoamylase activity), and $0.0156 \mathrm{M}$ cellobiose (lactose activity). Cellobiose is used as a substrate to determine membrane bound lactase activity independent of intracellular acid beta-glactosidase activity (18). Units of disaccharidase activity are $\mu$ mole substrate hydrolyzed per min (total enzyme activity) per total small intestine or per segment in the aboral gradient studies. Specific activity was expressed as activity units per $\mathrm{mg}$ protein. Protein was determined by the method of Lowry, et al. (9). Some small intestine was also examined by light microscopy on tissues fixed in $10 \%$ formalin, embedded in paraffin, sectioned along their longitudinal axis and stained with hemotoxylin-eosin.

Animals and reagents. Infant Sprague-Dawley rats with their mothers were obtained from King Animal Labs (Madison, Wisconsin). Cellobiose (Calbiochem), sucrose (Mallinckrodt), and maltose (Sigma Chemical Company), and Statzyme Glucose (Worthington) were purchased from the indicated sources.

Statistical analyses. Comparisons of the experimental and control littermates were made using the analysis of variance for a randomized block design (with litters as blocks) both of 16, 16DM $\mathrm{PGE}_{2}$ and $\mathrm{PGI}_{2}$. A priori comparisons between treatment versus controls were made using Dunnetts' procedure; $a$ priori tests for trend with dosage of $\mathrm{PGI}_{2}$ were tested with Fisher's least significant difference procedure; a posteriori contrasts were tested with Scheffe's procedure.

\section{RESULTS}

The animals administered $\mathrm{PGI}_{2}$ between 10-13 days demonstrated no differences in body, kidney, lung, liver or gut weights. No differences were seen in gut length or gut protein mass. But differences were seen in sucrase and maltase total activities and specific activities per $\mathrm{mg}$ protein per total small intestine (Table

Table 1. $P G I_{2}$-14-day-old

\begin{tabular}{|c|c|c|c|c|c|}
\hline \multirow{2}{*}{$\begin{array}{c}\text { Measured parameters } \\
\text { mean } \pm \text { S.E.M. } \\
n=5\end{array}$} & \multicolumn{4}{|c|}{ Dosages: $\mathrm{mg} / \mathrm{kg} /$ injection, three times a day } & \multirow{2}{*}{$\begin{array}{c}\text { Treatment } v s \\
\text { control } \\
P \text {-values }\end{array}$} \\
\hline & 0.0 & 0.1 & 0.2 & 0.3 & \\
\hline $\begin{array}{l}\text { Total intestinal lactase (U.E. }=\mu \mathrm{mole} / \mathrm{min} / \\
\text { total small intestine) }\end{array}$ & $1.78 \pm 0.09$ & $1.93 \pm 0.17$ & $2.01 \pm 0.17$ & $2.98 \pm 0.10$ & 0.052 \\
\hline Lactase (U.E./cm small intestine) & $0.044 \pm 0.002$ & $0.046 \pm 0.003$ & $0.046 \pm 0.003$ & $0.052 \pm 0.004$ & NS $^{1}$ \\
\hline Lactase specific activity (U.E./mg protein) & $0.017 \pm 0.001$ & $0.019 \pm 0.001$ & $0.019 \pm 0.002$ & $0.020 \pm 0.001$ & NS \\
\hline $\begin{array}{l}\text { Total intestinal maltase (U.E. }=\mu \text { mole } / \mathrm{min} / \\
\text { total small intestine) }\end{array}$ & $3.88 \pm 0.29$ & $7.44 \pm 1.03$ & $9.94 \pm 0.1 .86$ & $9.43 \pm 0.51$ & 0.001 \\
\hline Maltase (U.E./cm small intestine) & $0.097 \pm 0.008$ & $0.175 \pm 0.018$ & $0.228 \pm 0.041$ & $0.224 \pm 0.015$ & 0.001 \\
\hline Maltase specific activity (U.E./mg protein) & $0.037 \pm 0.003$ & $0.076 \pm 0.009$ & $0.093 \pm 0.015$ & $0.087 \pm 0.004$ & 0.001 \\
\hline $\begin{array}{l}\text { Total intestinal sucrase (U.E. }=\mu \mathrm{mole} / \mathrm{min} / \\
\text { total small intestine) }\end{array}$ & $0.140 \pm 0.038$ & $0.630 \pm 0.145$ & $1.04 \pm 0.405$ & $0.912 \pm 0.128$ & 0.01 \\
\hline Sucrase (U.E./cm small intestine) & $0.004 \pm 0.001$ & $0.015 \pm 0.003$ & $0.024 \pm 0.009$ & $0.022 \pm 0.003$ & 0.01 \\
\hline Sucrase specific activity (U.E./mg protein) & $0.0014 \pm 0.0004$ & $0.0064 \pm 0.0012$ & $0.0094 \pm 0.0035$ & $0.0086 \pm 0.0011$ & 0.01 \\
\hline
\end{tabular}

${ }^{1}$ NS, not significant.

Table 2. $\mathrm{PGI}_{2}-23$-day-old

\begin{tabular}{|c|c|c|c|c|c|}
\hline \multirow{2}{*}{$\begin{array}{c}\text { Measured parameters } \\
\text { mean } \pm \text { S.E.M. } \\
n=5\end{array}$} & \multicolumn{4}{|c|}{ Dosages: $\mathrm{mg} / \mathrm{kg} /$ injection, three times a day } & \multirow{2}{*}{$\begin{array}{c}\text { Treatment } v s \\
\text { control } \\
P \text { values }\end{array}$} \\
\hline & 0.0 & 0.1 & 0.2 & 0.3 & \\
\hline Body weight (g) & $59 \pm 0.9$ & $49 \pm 3.6$ & $48 \pm 4.0$ & $46 \pm 3.1$ & 0.01 \\
\hline Kidney weight (g) & $0.671 \pm 0.034$ & $0.616 \pm 0.024$ & $0.556 \pm 0.039$ & $0.563 \pm 0.035$ & 0.02 \\
\hline Intestinal weight $(\mathrm{g})$ & $5.38 \pm 0.30$ & $4.62 \pm 0.31$ & $3.69 \pm 0.30$ & $4.16 \pm 0.41$ & 0.001 \\
\hline Intestinal protein (mg) & $523 \pm 21$ & $321 \pm 31$ & $332 \pm 44$ & $299 \pm 43$ & 0.001 \\
\hline $\begin{array}{l}\text { Total intestinal lactase (U.E. }=\mu \mathrm{mole} / \mathrm{min} / \\
\text { total small intestine) }\end{array}$ & $5.58 \pm 0.884$ & $4.39 \pm 1.13$ & $3.91 \pm 0.771$ & $2.83 \pm 0.321$ & 0.03 \\
\hline Lactase (U.E./cm small intestine) & $0.086 \pm 0.015$ & $0.065 \pm 0.017$ & $0.061 \pm 0.012$ & $0.042 \pm 0.048$ & 0.03 \\
\hline Lactase specific activity (U.E./mg protein) & $0.011 \pm 0.002$ & $0.013 \pm 0.003$ & $0.013 \pm 0.003$ & $0.011 \pm 0.002$ & $\mathrm{NS}^{1}$ \\
\hline $\begin{array}{l}\text { Total intestinal maltase (U.E. }=\mu \text { mole } / \mathrm{min} / \\
\text { total small intestine) }\end{array}$ & $6.95 \pm 1.81$ & $5.14 \pm 1.86$ & $3.56 \pm 1.24$ & $4.18 \pm 0.45$ & 0.005 \\
\hline Maltase (U.E./cm small intestine) & $0.107 \pm 0.014$ & $0.076 \pm 0.012$ & $0.055 \pm 0.008$ & $0.062 \pm 0.006$ & 0.005 \\
\hline Maltase specific activity (U.E./mg protein) & $1.35 \pm 0.19$ & $1.60 \pm 0.22$ & $1.12 \pm 0.22$ & $1.47 \pm 0.17$ & NS \\
\hline $\begin{array}{l}\text { Total intestinal sucrase (U.E. }=\mu \text { mole } / \mathrm{min} / \\
\text { total small intestine) }\end{array}$ & $172 \pm 10$ & $144 \pm 38$ & $120 \pm 20$ & $118 \pm 14$ & 0.02 \\
\hline Sucrase specific activity (U.E./mg protein) & $0.332 \pm 0.029$ & $0.455 \pm 0.049$ & $0.358 \pm 0.043$ & $0.413 \pm 0.049$ & NS \\
\hline
\end{tabular}

\footnotetext{
NS, not significant.
} 
Table 3. 16,16 dimethyl $P G E_{2}$ 16-day-old

\begin{tabular}{lccc}
\hline \multicolumn{1}{c}{$\begin{array}{c}\text { Measured paramtners } \\
\text { mean } \pm \text { S.E.M. } \\
n=5\end{array}$} & \multicolumn{2}{c}{$\begin{array}{c}\text { Dosages: } 0.33 \mu \mathrm{g} \mathrm{PGE}_{2} \cdot \mathrm{min}^{-1} \cdot \mathrm{kg}^{-1} \text { from } \\
\text { day } 10 \text { of life }\end{array}$} & $\begin{array}{c}P \text { value difference } \\
\text { between groups }\end{array}$ \\
\cline { 2 - 4 } & Control & Experimental' & $\mathrm{NS}^{2}$ \\
Sacrifice body weights (g) & $30.8 \pm 2.3$ & $26.0 \pm 1.6$ & 0.035 \\
Change in body weight (g) day 10-16 & $11.2 \pm 3.1$ & $4.3 \pm 1.0$ & 0.045 \\
Liver weight (g) & $1.35 \pm 0.05$ & $1.20 \pm 0.04$ & $\mathrm{NS}$ \\
Intestinal protein (mg) & $66 \pm 7.2$ & $96 \pm 7.2$ & $\mathrm{NS}$ \\
Total intestinal lactase (U.E. $=\mu$ mole/min/total small intestine) & $1.80 \pm 0.238$ & $2.011 \pm 0.458$ & $\mathrm{NS}$ \\
Lactase (U.E./cm small intestine) & $0.027 \pm 0.004$ & $0.0437 \pm 0.010$ & $\mathrm{NS}$ \\
Lactase specific activity (U.E./mg protein) & $0.027 \pm 0.002$ & $0.022 \pm 0.005$ & 0.053 \\
Total intestinal maltase (U.E. $=\mu$ mole/min/total small intestine) & $14.92 \pm 0.52$ & $34.48 \pm 0.69$ & 0.068 \\
Maltase (U.E./cm small intestine) & $0.32 \pm 0.121$ & $0.753 \pm 0.167$ & $\mathrm{NS}$ \\
Maltase specific activity (U.E./mg protein) & $0.232 \pm 0.082$ & $0.386 \pm 0.099$ & 0.01 \\
Total intestinal sucrase (U.E. $=\mu$ mole/min/total small intestine) & $2.22 \pm 0.12$ & $9.93 \pm 0.21$ & 0.02 \\
Sucrase (U.E./cm small intestine) & $0.048 \pm 0.028$ & $0.217 \pm 0.051$ & 0.064 \\
Sucrase specific activity (U.E./mg protein) & $0.035 \pm 0.019$ & $0.111 \pm 0.031$ & \\
\hline
\end{tabular}

$n=4$.

${ }^{2}$ NS, not significant.

MALTASE AND SUCRASE

ABORAL GRADIENT SPECIFIC ACTIVITY PER II PROTEIN

$0.3 \mathrm{mg}-\mathrm{kg}^{-1} \mathrm{PGI}_{2}$ vS CONTROL 23 DAYS OF AGE

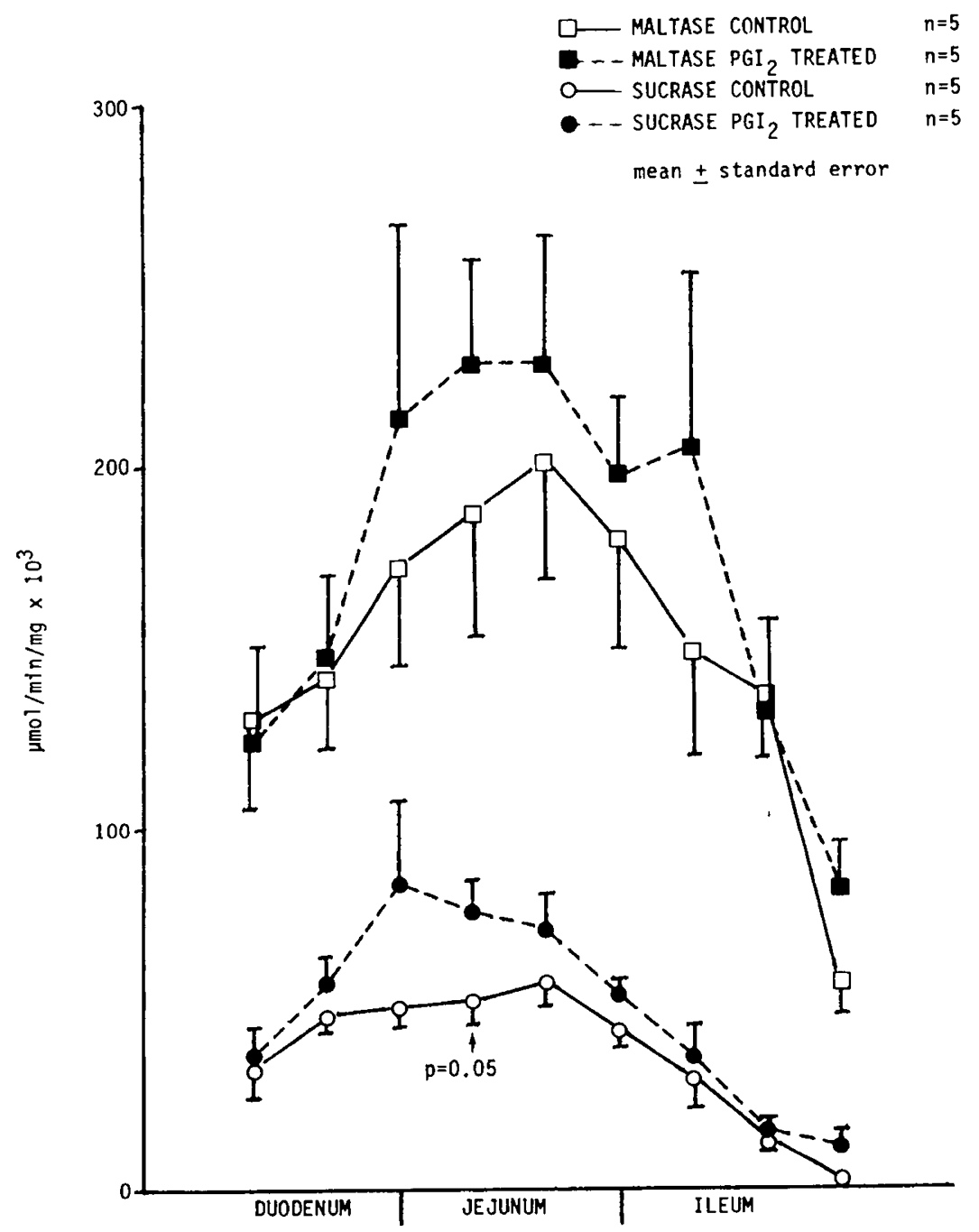

Fig. 1. Aboral gradients of sucrase and maltase (glucoamylase) activities in animals administered $0.3 \mathrm{mg} / \mathrm{kg} /$ dose three times a day $\nu s$ controls. 
1). An increasing trend in the activity of lactase was also demonstrated in the animals administered $\mathrm{PGI}_{2}$. Of interest are the differences between the 23-day-old control and $\mathrm{PGI}_{2}$-administered animals in terms of body, kidney, gut weights and gut protein mass (Table 2). No differences in liver or lung weights or gut lengths were detected in the 23-day-old animals administered $\mathrm{PGI}_{2}$. Biochemical differences in the animals administered $\mathrm{PGI}_{2}$ between 19-22 days consisted of significant decreases in total small intestinal activities of lactase, sucrase, and maltase; however, the specific activities of these enzymes per $\mathrm{mg}$ protein did not demonstrate differences (Table 2).

The results of the studies of $16,16 \mathrm{DM} \mathrm{PGE}_{2}$-administered animals are seen in Table 3. Administration of 16, $16 \mathrm{DM} \mathrm{PGE}_{2}$ by continuous minipump infusion significantly decreased change in total body and liver weights. Sucrase and maltase were increased in terms of total activity; however, sucrase and maltase specific activities per $\mathrm{mg}$ protein were not increased in the 16-day-old animals. Lactase activities were not significantly altered by the administration of $16,16 \mathrm{DM} \mathrm{PGE}_{2}$.

Consistently elevated trends in sucrase and maltase were seen across the entire aboral gradient in the animals administered $\mathrm{PGI}_{2}$ with the greatest differences seen in the mid-small intestinal regions (Fig. 1).

No differences in histology were seen between control and experimental animals by light microscopy. Mitotic activity was sparse in both control and experimental groups and no discernible differences were appreciated.

\section{DISCUSSION}

Because prostaglandins closely related to $\mathrm{PGI}_{2}$ and $16,16 \mathrm{DM}$ $\mathrm{PGE}_{2}$ are commonly used for both short and long term maintenance of ductal patency, a better knowledge of their extraductal effects is desirable.

Data obtained in this investigation demonstrated that administration of $\mathrm{PGI}_{2}$ and $16,16 \mathrm{DM} \mathrm{PGE}_{2}$ to preweaned and weanling rat pups is associated with alterations in growth and markers of biochemical development. Whether similar effects of the prostaglandins would be seen in human neonates remains speculative.

Sucrase activity has classically been used as a marker of intestinal biochemical development. The administration of pharmacologic doses of glucocorticoid (4) or thyroxine (7) will evoke a precocious increase in sucrase.

In a previous study, prostaglandins $\left(\mathrm{PGE}_{1}\right.$ and $\mathrm{PGE}_{2}$ at doses of $1-10 \mu \mathrm{g}$ per $\mathrm{kg}$ ) were shown to cause an increased release of disaccharidase into the lumen of the small intestine $(9,11)$. In our study, exogenously administered prostaglandins were shown to be associated with altered disaccharidase activity in the intestine itself across the entire aboral gradient.

Of interest is the fact that prostaglandins may increase intestinal mitogenic activity (6). The well-known coincident increase in cell migration rate (8) and sucrase activity that occurs at the time of weaning in the rat may well be mediated by similar mechanisms, such as that brought about by the administration of cortisone (5). Perhaps prostaglandins and glucocorticoids act upon similar messengers or receptors, which control disaccharidase activity and enterocyte proliferation.
Whether the prostaglandins in this study cause a precocious increase in sucrase activity through direct action or through stimulation of glucocorticoid, thyroxine, a second messenger such as cyclic nucleotides, nutritional factors, or mesenteric vasodilators remains to be elucidated.

In summary, the prostaglandins are ubiquitous compounds in the body. When administered exogenously, they may alter growth and biochemical development in the rat. The precocious increase in disaccharidase activity represents a potentially beneficial effect, but the mechanisms of this increase are poorly understood and warrant further investigation.

\section{REFERENCES AND NOTES}

1. Bennett, A. and Fleschler, B.: Prostaglandins and the gastrointestinal tract. Gastroenterology, 59: 790 (1970).

2. Bennett, A., Murray, J. G., and Wyllie, J. H.: Occurrence of $\mathrm{PGE}_{2}$ in the human stomach, and the study of its effects on human isolated gastric mucosa. Br. J. Pharmacol. Chemother., 32: 339 (1968).

3. Bunting, G., Gryglewski, R., Moncada, S., Vane, J. R. Arterial Walls generate from prostaglandin endoperoxides a substance (PGX) which relaxed strips of mesenteric and coeliac arteries and inhibits platelet aggregation. Prostaglandins, 12: 897 (1976)

4. Doell, R. G., and Kretchmer, N.: Intestinal invertase: precocious development of activity after injection of hydrocortisone. Science, 143: 42 (1964).

5. Herbst, J. J. and Koldovsky, O.: Cell migration and cortisone induction of sucrase acting in jejunun and ileum. Biochem. J., 126: 471 (1976).

6. Johnson, L. R. and Guthrie, P. O.: Mucosal DNS Synthesis: effect of cholecystokinin and 16, 16-dimethyl prostaglandin $E_{2}$ on RNA and DNA of gastric and duodonal mucosa. Gastroenterology, 70: 59 (1976).

7. Koldovsky, O., Jumawan, J. and Palmieri, M.: Thyroxine-evoked precocious decrease of acid hydralases in the ileum of suckling rats. Proc. Soc. Exp. Biol. Med., 146: 661 (1974)

8. Koldovsky, O., Sunshine, P. and Kretchmer, N.: Cellular migration of intestinal epithelia in suckling and weaned rats. Nature (London), 212: 1389 (1966).

9. Lowry, O. H., Rosenbrough, N. J., Farr, A. J., Randall, R. J. Protein measurement with folin phenol reagent. J. Biochem., 193: 265 (1951).

10. Menguy, R. and Disbeillets, L.: Role of Inhibition of gastric mucous secretion in the phenomenon of gastric mucosal injury by Indomethacin. Am. J. Dig. Dis. 12: 862 (1967).

11. Mirhom, R., Eloy, R., Vaultier, J. P., Amanna, A., Clendinen, G., and Grenier, J. E.: Prostaglandins $E$ and $\mathrm{E}_{2}$ stimulate release of brush border enzymes. Prostaglandins, 14: 463 (1977).

12. Pace-Asciak, C., Nashat, M., and Menon, N. K.: Transformation of prostaglandin $\mathrm{G}_{2}$ into 6 (9)-oxy-11, 15-dihydroxyprosta-7, 13-dienoic acid by the rat stomach fundus. Biochem. Biophys. Acta, 424: 323 (1976).

13. Peskar, B. M.: On the synthesis of prostaglandins by human gastric mucosa and its modification by drugs. Biochem. Biophys. Acta, 487: 307 (1977).

14. Robert, A., Hanchar, A. J., Lancaster, C., Nezamis, J. E. Antisecretory and cytoprotective effects of prostacyclin $\left(\mathrm{PGI}_{2}\right)$. Fed. Proc., 37: 460 (1978).

15. Robert, A.: Prostaglandins and the digestive system. In: Ramwell PW (ed.): The Prostaglandins, page 225 (Plenum Press, New York, 1968).

16. Ruwart, M.: The Upjohn Company, Kalamazoo, Michigan (Unpublished results).

17. Senedecor, G. W. and Cochran, W. G.: Statistical Methods, 6th ed. 1967 (The Iowa State University Press, Ames, Iowa).

18. Tsuboi, K. K., Schwarz, S. M., Burrill, P. H., Kwong, L. K. and Sunshine, P.: Sugar hydrolases of the infant rat intestine and their arrangement on the brush border membrane. Biochem. Biophys. Acta, 554: 234 (1979).

19. The authors wish to thank Drs. Konrad Soergel and Otakor Koldovsky for their helpful comments and Frances Sommer for typing the manuscript.

20. Requests for reprints should be addressed to: Dr. Josef Neu, Department of Pediatrics, Milwaukee Children's Hospital, 1700 West Wisconsin Avenue, P. O. Box 1997, Milwaukee, Wisconsin 53201.

21. This research supported by a grant from the Medical College of Wisconsin Milwaukee, Wisconsin 53226

22. Received for publication April 14, 1982.

23. Accepted for publication December 6, 1982 . 